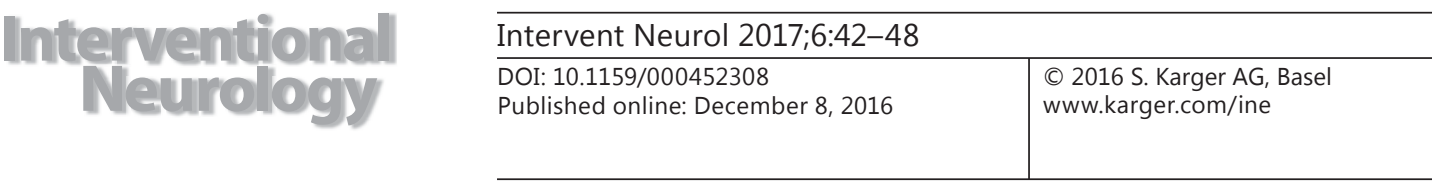

\title{
Open-Label Phase I Clinical Study to Assess the Safety and Efficacy of Cilostazol in Patients Undergoing Internal Carotid Artery Stent Placement
}

\author{
Ameer E. Hassan ${ }^{a}$ Haralabos Zacharatos $^{b} \quad$ Mikayel Grigoryan $^{c}$ \\ Wondwossen G. Tekle ${ }^{a}$ Amir Khan ${ }^{d}$ Farhan Siddiq $^{e}$ Gustavo J. Rodriguez ${ }^{f}$ \\ Ramachandra Tummalag Bharathi Jagadeesang ${ }^{9}$ M. Fareed K. Suri ${ }^{\text {h }}$ \\ Adnan I. Qureshi ${ }^{i}$ \\ a Valley Baptist Brain and Spine Network, University of Texas Health Science Center - San \\ Antonio, Harlingen, TX, bVassar Brothers Medical Center, Poughkeepsie, NY, ' Glendale Adventist \\ Medical Center, Glendale, CA, dUCSF Fresno, Fresno, CA, e Harris Methodist Hospital, Fort \\ Worth, TX, ${ }^{\mathrm{f}}$ Texas Tech, El Paso, TX, ${ }^{g}$ University of Minnesota Medical Center, Minneapolis, MN, \\ ${ }^{h}$ Centracare health, St. Cloud, MN, and 'Zeenat Qureshi Stroke Research Center, University of \\ Minnesota, Minneapolis, MN, USA
}

\section{Keywords}

Aspirin · Carotid stenosis · Cerebral infarction · Cilostazol · Clopidogrel · Internal carotid stent placement $\cdot$ Transient ischemic attack

\begin{abstract}
Background: One-month dual antiplatelet treatment, with aspirin and clopidogrel, following internal carotid artery stent placement is the current standard of care to prevent in-stent thrombosis. Cilostazol, an antiplatelet drug, has been demonstrated to have a safety profile comparable to aspirin and clopidogrel. Objective: To evaluate the safety and clinical efficacy of cilostazol and aspirin therapy following internal carotid artery stent placement up to 1 month postprocedure. Methods: A phase I open-label, nonrandomized two-center prospective study was conducted. All subjects received aspirin ( $325 \mathrm{mg} /$ day) and cilostazol ( $200 \mathrm{mg} /$ day) 3 days before extracranial stent placement. Two antiplatelet agents were continued for 1 month postprocedure followed by aspirin daily monotherapy. The primary efficacy end point was the 30-day composite occurrence of death, cerebral infarction, transient ischemic attack, and in-stent thrombosis. The primary safety end point was bleeding. Results: Twelve subjects (mean age \pm SD, $66 \pm 12$ years; 9 males) were enrolled and underwent internal carotid artery angioplasty and stent placement. None of the subjects who successfully followed the study protocol experienced any complications at the 1- and 3-month follow-ups. One patient had a protocol deviation due to concurrent use of enoxaparin ( $1 \mathrm{mg} / \mathrm{kg}$ twice daily) in addition to aspirin and cilostazol, resulting in a fatal symptomatic intracerebral hemorrhage
\end{abstract}


following successful stent placement on postprocedure day 1 . One patient discontinued cilostazol after the first dose secondary to dizziness. Conclusion: The use of cilostazol and aspirin for internal carotid artery stent placement appears to be safe, but protocol compliance needs to be emphasized.

(C) 2016 S. Karger AG, Basel

\section{Introduction}

Cilostazol, an antiplatelet medication different from aspirin and clopidogrel, selectively inhibits phosphodiesterase III, increases intraplatelet intracellular cyclic $3^{\prime}$-5'-adenosine monophosphate levels, activates protein kinase A, and decreases intracellular calcium levels $[1,2]$. The antiplatelet effect of cilostazol, a prodrug, begins after it is hepatically metabolized. It has been demonstrated to have pleiotropic effects, reducing smooth muscle proliferation and intimal hyperplasia and causing vasodilation [3-5]. Cilostazol, also known as Pletal, has been approved in the United States since 1999 for the treatment of symptomatic peripheral arterial disease [6]. The Cilostazol Stroke Prevention Study (CSP 2) demonstrated that cilostazol $(200 \mathrm{mg} /$ day) was associated with fewer incidence of hemorrhagic events compared to aspirin (81 mg/day) for the prevention of stroke after an initial ischemic stroke (1.2 vs. $0.036 \%$ ) with similar risk reduction for ischemic events [7].

The 2011 multispecialty Guidelines on the Management of Patients with Extracranial Carotid and Vertebral Artery Disease: Executive Summary recommended dual antiplatelet therapy with aspirin (81-325 mg daily) plus clopidogrel (75 mg daily) prior to and for a minimum of 30 days after carotid artery stent placement; for patients intolerant of clopidogrel, ticlopidine (250 mg twice daily) may be substituted based on $\mathrm{Clevel}$ evidence [8]. The current guidelines on carotid artery stent placement do not mention cilostazol as an alternative to clopidogrel [9]. In the coronary circulation, cilostazol reduced the incidence of restenosis after balloon angioplasty and bare metal stent placement compared with aspirin and clopidogrel or ticlopidine [10-12]. Similarly, the combination of cilostazol and aspirin had lower rates of restenosis following carotid artery stent placement compared with aspirin and clopidogrel or ticlopidine in an observational study [13]. We performed a phase I open-label, nonrandomized two-center prospective study, to determine the safety of 1-month treatment with aspirin (325 mg/day) and cilostazol (200 mg/day) following extracranial stent placement.

\section{Methods}

We conducted a phase I open-label, nonrandomized two-center (Hennepin County Medical Center, Minneapolis, MN and University of Minnesota Medical Center, Minneapolis, MN) prospective study with the approval of the institutional review board of both hospitals. All subjects signed an informed consent prior to participating in the study. Each patient received aspirin ( $325 \mathrm{mg} /$ day) and cilostazol (200 mg/day) for 3 days before extracranial stent placement. The two antiplatelet agents were continued for 1 month postprocedure and then aspirin $(325 \mathrm{mg}$ ) daily monotherapy was continued thereafter. Study subjects were 18 years of age or older, with a baseline modified Rankin score of $0-2$, who were scheduled to undergo extracranial internal carotid artery stent placement with or without balloon angioplasty for symptomatic or asymptomatic carotid artery stenosis. A distal embolic protection device was used with every stent placed. The internal carotid stenosis had to be greater than $50 \%$ and less than or equal to $99 \%$ as measured by the North American Symptomatic Carotid Endarterectomy Trial (NASCET) [14]. Subjects who received a carotid stent had high surgical risk features such as clinically significant cardiac disease (congestive heart failure, abnormal stress test, or need for open-heart surgery), severe pulmonary disease, contralateral carotid occlusion, contralateral laryngeal nerve palsy, previous radical neck surgery or radiation therapy to the neck, recurrent stenosis after endarterectomy, and age greater than or equal to 80 years [15]. Also, stenting was preferred when there was a high carotid artery bifurcation, at the level of the $\mathrm{C} 2$ vertebra and above. 
Subjects were excluded from participating in the study if they had a history of bleeding diathesis, including disorders treated by warfarin therapy (however, those who had received warfarin but had stopped taking the medication 3 days before the procedure and had an international normalized ratio less than 1.2 were eligible for inclusion). Similarly, subjects were excluded if they had severe hypertension (defined as systolic blood pressure greater than $180 \mathrm{~mm} \mathrm{Hg}$ or diastolic blood pressure greater than $100 \mathrm{~mm} \mathrm{Hg}$, despite therapy), had a major surgery within the previous 6 weeks, or had a previous history of a hemorrhagic stroke. Pregnant patients or women who were breast-feeding were excluded from the study. Subjects were also excluded if they had gastrointestinal or genitourinary bleeding within the previous 30 days of treatment, had platelets less than 30,000, and/or had congestive heart failure.

The primary efficacy end point was the 30-day composite occurrence of death, cerebral infarction, transient ischemic attack, and in-stent thrombosis requiring unplanned endovascular revascularization procedure. The primary safety end point was bleeding. Bleeding complications were classified as major, moderate, or minor according to criteria used by the Thrombolysis in Myocardial Infarction trial group [16]. Major bleeding was defined as any intracranial hemorrhage or a decrease in hemoglobin level of less than $5 \mathrm{~g} / \mathrm{dL}$ that resulted in hemodynamic compromise requiring treatment. Moderate bleeding was defined by the need for transfusion. Minor bleeding was defined as any decrease in hemoglobin level of 3 to $5 \mathrm{~g} / \mathrm{dL}$, not requiring transfusion or causing hemodynamic compromise. The age of the subjects, gender, medical comorbidities, length of intensive care stay (days), length of hospital stay (days), clinical indication for treatment, clinical presentation, and location of carotid stenosis were abstracted from the electronic medical record. The intraprocedural details regarding the stent deployed, whether pre- or post-balloon angioplasty was utilized as well as the balloon type, the posttreatment stenosis, and complications were abstracted from the medical record. Similarly, the followup complications and 1-month modified Rankin scale scores were also documented for each patient.

\section{Statistical Analysis}

The data is presented in a descriptive presentation. The mean value with standard deviation (SD) was presented for continuous variables including age and pre-stent and post-stent stenosis with or without angioplasty. The total number of immediate procedure-related and postprocedure follow-up complications were documented and counted. Postprocedure follow-up complications were defined as any complication that occurred after the immediate procedure and within the follow-up time period.

\section{Results}

Twelve subjects (mean age \pm SD, $66 \pm 12$ years; 9 men) were enrolled using the study protocol and underwent internal carotid artery stent placement with or without angioplasty with a distal embolic protection device. All the patients who received a carotid artery stent had stenosis secondary to extracranial atherosclerotic disease; there were no carotid stents placed for an arterial dissection. The procedure was performed in the right and left extracranial internal carotid arteries in 7 (58\%) and 5 (42\%) subjects, respectively. All the subjects were treated using the Nitinol PRECISE ${ }^{\circledR}$ PRO RX ${ }^{\circledR}$ Stent system (Johnson and Johnson; New Jersey) except for one patient who was treated with an Xpert stent (Abbott; Illinois, USA). The decision to use the 4-mm Xpert stent (Abbott) was based on the size of the internal carotid artery. The pre-stent percent stenosis and post-stent percent stenosis represented as mean \pm SD were $79 \pm 10 \%$ and $9 \pm 10 \%$, respectively. Pre-stent angioplasty was used in 5 subjects. Post-stent angioplasty was used in 5 subjects. There was one patient who received pre-angioplasty dilation of the stenotic lesion followed by post-stent angioplasty for further lesion dilation. One patient had stent placement alone, without pre- or post-angioplasty (see Table 2). Patients 3 and 6 represent the same patient but the extracranial carotid arteries were treated at separate time points, respectively, and were treated as two subjects (see Table 1). Other comorbidities among study subjects included: hypertension in 10 (83\%), hyperlipidemia in 9 (75\%), atrial fibrillation in 2 (17\%), diabetes mellitus in 5 (42\%), history of recent ischemic stroke and/or TIA in 7 (58\%), congestive heart failure in 3 (25\%), and tobacco dependence in 4 (33\%) subjects. 
Table 1. Baseline and angiographic characteristics of the study subjects recruited in the phase I trial

\begin{tabular}{|c|c|c|c|c|c|}
\hline Patient & $\begin{array}{l}\text { Age, } \\
\text { years/ } \\
\text { sex }\end{array}$ & Clinical presentation & Cardiovascular risk factors & $\begin{array}{l}\text { Lesion } \\
\text { site }\end{array}$ & $\begin{array}{l}\text { Pre- } \\
\text { treatment } \\
\text { stenosis, \% }\end{array}$ \\
\hline 1 & $63 / \mathrm{M}$ & $\begin{array}{l}1 \text { month prior to stenting had } \\
\text { multiple MRI-proven subacute and } \\
\text { acute infarcts in right cerebral } \\
\text { hemisphere; refused CEA }\end{array}$ & DM type II, hypertension & Right ICA & 90 \\
\hline 2 & $60 / \mathrm{M}$ & $\begin{array}{l}\text { Multiple spells of amaurosis fugax of } \\
\text { right eye }\end{array}$ & $\begin{array}{l}\text { Occluded left ICA, HTN, HPLD, severe } \\
\text { COPD }\end{array}$ & Right ICA & 75 \\
\hline 3 & $56 / \mathrm{M}$ & $\begin{array}{l}\text { Acute ischemic stroke with right-side } \\
\text { hemiparesis and dysarthria }\end{array}$ & $\begin{array}{l}\text { Nine years prior had neck radiation for } \\
\text { Hodgkin's lymphoma; HTN; tobacco } \\
\text { dependent }\end{array}$ & Left ICA & 85 \\
\hline 4 & $75 / \mathrm{F}$ & $\begin{array}{l}\text { TIA: sensory alteration of the right } \\
\text { side of the body }\end{array}$ & HTN, A. Fib., CHF, DM type II, HLPD & Left ICA & 80 \\
\hline 5 & $50 / \mathrm{M}$ & $\begin{array}{l}\text { Acute ischemic stroke with left sided } \\
\text { hemiparesis }\end{array}$ & HTN, HLPD & Right ICA & 70 \\
\hline 6 & $56 / \mathrm{M}$ & Asymptomatic & $\begin{array}{l}\text { Acute ischemic stroke secondary to a } \\
\text { severe left ICA 85\% stenosis } 2 \text { months } \\
\text { prior to stenting; } 9 \text { years prior had neck } \\
\text { radiation for Hodgkin's lymphoma; HTN; } \\
\text { tobacco dependent }\end{array}$ & Right ICA & 85 \\
\hline $7^{* *}$ & $63 / F$ & $\begin{array}{l}\text { TIA: left hand weakness a week prior } \\
\text { to stenting }\end{array}$ & A. Fib., HTN, CHF, DM type II & Right ICA & 80 \\
\hline $8^{* *}$ & $72 / \mathrm{M}$ & Amaurosis fugax of the left eye & $\begin{array}{l}\text { HTN, HLPD, coronary artery disease, DM } \\
\text { type II }\end{array}$ & Left ICA & 60 \\
\hline 9 & $91 / \mathrm{F}$ & $\begin{array}{l}\text { TIA: intermittent word finding } \\
\text { difficulties }\end{array}$ & $\begin{array}{l}\text { HTN, DM type II, ischemic stroke (2004); } \\
\text { coronary artery disease with CABG }\end{array}$ & Left ICA & 75 \\
\hline 10 & $57 / \mathrm{M}$ & $\begin{array}{l}\text { Right corona radiata ischemic stroke } \\
\text { with left hemiparesis }\end{array}$ & HTN, DM type II & Left ICA & 99 \\
\hline 11 & $71 / \mathrm{M}$ & Asymptomatic & $\begin{array}{l}\text { HTN, HPLD, right ICA stenosis treated } \\
\text { with carotid stent previously, CHF }\end{array}$ & Right ICA & 80 \\
\hline 12 & $81 / \mathrm{M}$ & $\begin{array}{l}\text { Acute ischemic stroke with left arm } \\
\text { and leg hemiparesis }\end{array}$ & $\begin{array}{l}\text { Had poor medical follow-up. Did not have } \\
\text { any prior medical history }\end{array}$ & Right ICA & 70 \\
\hline
\end{tabular}

Patients No. 3 and 6 represent the same patient treated at different time points. The 2 subjects with asterisks were not included in the study analysis because they did not complete the study. A. Fib., atrial fibrillation; CABG, coronary artery bypass graft; CEA, carotid endarterectomy; CHF, congestive heart failure; COPD, chronic obstructive pulmonary disease; DM, diabetes mellitus; F, female; HLPD, hyperlipidemia; HTN, hypertension; ICA, internal carotid artery; M, male; MRI, magnetic resonance imaging; TIA, transient ischemic attack.

All of the study subjects who successfully followed the study protocol completed the study without any change in their pre- and posttreatment modified Rankin score and did not experience any intracerebral hemorrhage, systemic bleeding complications, ischemic stroke, transient ischemic attack, or in-stent thrombosis at the 1-month and 3-month follow-up. Prior to stent placement, one patient discontinued cilostazol after the first dose secondary to nonspecific dizziness. There was a protocol deviation in one patient due to concurrent use of enoxaparin ( $1 \mathrm{mg} / \mathrm{kg}$ twice daily) in addition to aspirin and cilostazol. The patient suffered a fatal symptomatic intracerebral hemorrhage following successful stent placement on postprocedure day 1. A third patient was successfully enrolled in the study but the cilostazol was discontinued by her cardiologist 5 days after the successful and uncomplicated stent placement. 
Table 2. Procedural information and clinical outcomes in study subjects

\begin{tabular}{|c|c|c|c|c|c|c|c|c|}
\hline Patient & Angioplasty performed & $\begin{array}{l}\text { Stent (type, } \\
\text { size) }\end{array}$ & $\begin{array}{l}\text { Post- } \\
\text { treatment } \\
\text { stenosis, } \\
\%\end{array}$ & $\begin{array}{l}\text { Intra- } \\
\text { procedural } \\
\text { com-plication }\end{array}$ & $\begin{array}{l}\text { Post } \\
\text { procedure } \\
\text { death }\end{array}$ & $\begin{array}{l}\text { Bleeding compli- } \\
\text { cations, stroke, TIA, stroke } \\
\text { or in-stent thrombosis/ } \\
\text { occlusion at } 1 \text { month } \\
\text { posttreatment }\end{array}$ & $\begin{array}{l}\text { ICU/total } \\
\text { hospital } \\
\text { stay, days }\end{array}$ & $\begin{array}{l}1 \text { month } \\
\text { modified } \\
\text { Rankin scale } \\
\text { score }\end{array}$ \\
\hline 1 & $\begin{array}{l}\text { Maverick }^{\mathrm{a}}, \\
3 \mathrm{~mm} \times 20 \mathrm{~mm}\end{array}$ & $\begin{array}{l}\text { Precise, } \\
7 \mathrm{~mm} \times 40 \mathrm{~mm}\end{array}$ & 20 & 0 & 0 & 0 & $1 / 1$ & 0 \\
\hline 2 & $\begin{array}{l}\text { Aviator }^{\mathrm{a}} \\
4 \mathrm{~mm} \times 20 \mathrm{~mm} \text {; } \\
\text { Aviator } \\
5 \mathrm{~mm} \times 20 \mathrm{~mm}\end{array}$ & $\begin{array}{l}\text { Precise, } \\
8 \mathrm{~mm} \times 30 \mathrm{~mm}\end{array}$ & 10 & 0 & 0 & 0 & $1 / 1$ & 0 \\
\hline 3 & $\begin{array}{l}\text { Viatrac }^{\mathrm{b}}, \\
4 \mathrm{~mm} \times 20 \mathrm{~mm}\end{array}$ & $\begin{array}{l}\text { Precise, } \\
7 \mathrm{~mm} \times 30 \mathrm{~mm}\end{array}$ & 10 & 0 & 0 & 0 & $2 / 9$ & 0 \\
\hline 4 & $\begin{array}{l}\text { Aviator }{ }^{\mathrm{a}} \\
4.0 \mathrm{~mm} \times 30 \mathrm{~mm}\end{array}$ & $\begin{array}{l}\text { Precise, } \\
7 \mathrm{~mm} \times 30 \mathrm{~mm}\end{array}$ & 25 & 0 & 0 & 0 & $1 / 1$ & 0 \\
\hline 5 & $\begin{array}{l}\text { Viatrac } \\
4.5 \mathrm{~mm} \times 20 \mathrm{~mm}\end{array}$ & $\begin{array}{l}\text { Precise, } \\
8 \mathrm{~mm} \times 30 \mathrm{~mm}\end{array}$ & 0 & 0 & 0 & 0 & $1 / 3$ & $\begin{array}{l}2 \\
\text { (baseline) }\end{array}$ \\
\hline 6 & $\begin{array}{l}\text { Viatrac }^{b}, \\
4 \mathrm{~mm} \times 20 \mathrm{~mm}\end{array}$ & $\begin{array}{l}\text { Precise, } \\
7 \mathrm{~mm} \times 40 \mathrm{~mm}\end{array}$ & 20 & 0 & 0 & 0 & $1 / 1$ & 0 \\
\hline $7^{* *}$ & $\begin{array}{l}\text { Viatrac }^{\mathrm{a}}, \\
4 \mathrm{~mm} \times 30 \mathrm{~mm}\end{array}$ & $\begin{array}{l}\text { Precise, } \\
7 \mathrm{~mm} \times 30 \mathrm{~mm}\end{array}$ & 0 & 0 & 1 & - & $1 / 2$ & 6 \\
\hline $8^{* *}$ & None & $\begin{array}{l}\text { Xpert, } \\
4 \mathrm{~mm} \times 20 \mathrm{~mm}\end{array}$ & 0 & 0 & 0 & 0 & $1 / 1$ & 0 \\
\hline 9 & $\begin{array}{l}\text { Aviator }{ }^{\mathrm{a}} \\
4.5 \mathrm{~mm} \times 15 \mathrm{~mm}\end{array}$ & $\begin{array}{l}\text { Precise, } \\
7 \mathrm{~mm} \times 40 \mathrm{~mm}\end{array}$ & 20 & 0 & 0 & 0 & $1 / 1$ & 0 \\
\hline 10 & $\begin{array}{l}\text { Maverick }^{\mathrm{a}}, \\
3 \mathrm{~mm} \times 20 \mathrm{~mm}\end{array}$ & $\begin{array}{l}\text { Precise, } \\
7 \mathrm{~mm} \times 30 \mathrm{~mm}\end{array}$ & 0 & 0 & 0 & 0 & $1 / 2$ & 0 \\
\hline 11 & $\begin{array}{l}\text { Aviator }{ }^{\mathrm{b}}, \\
5 \mathrm{~mm} \times 30 \mathrm{~mm}\end{array}$ & $\begin{array}{l}\text { Precise, } \\
6 \mathrm{~mm} \times 40 \mathrm{~mm}\end{array}$ & 0 & 0 & 0 & 0 & $1 / 1$ & 0 \\
\hline 12 & $\begin{array}{l}\text { Viatrac } \\
5 \mathrm{~mm} \times 30 \mathrm{~mm}\end{array}$ & $\begin{array}{l}\text { Precise, } \\
7 \mathrm{~mm} \times 40 \mathrm{~mm}\end{array}$ & 0 & 0 & 0 & 0 & $1 / 7$ & 1 \\
\hline
\end{tabular}

The 2 subjects with asterisks were not included in the study analysis because they did not complete the study.

a Pre-stent balloon. ${ }^{\mathrm{b}}$ Post-stent balloon.

\section{Discussion}

Ischemic stroke can occur during or after extracranial internal carotid artery stent placement in rates varying from 4 to $10 \%$ depending on patient characteristics due to thromboembolic complications [17]. Clopidogrel and aspirin are the most commonly utilized antiplatelet medications prescribed prior to and following extracranial internal carotid artery stent placement to prevent in-stent thrombosis. This is the first phase I study in the United States that demonstrated the feasibility of using cilostazol and aspirin dual antiplatelet therapy to prevent in-stent thrombosis following internal carotid artery stenting. When adhering to the treatment regiment, cilostazol and aspirin appeared to be a safe treatment alternative to aspirin and clopidogrel, but such an observation requires further prospective studies to demonstrate efficacy in prevention of ischemic events. There are few reports that have examined the efficacy of dual antiplatelet treatment with aspirin and cilostazol specifically following carotid stent placement, with the majority of studies focusing on patients with coronary artery disease who have coronary stents placed [18]. 
Hassan et al.: Open-Label Phase I Clinical Study to Assess the Safety and Efficacy of

Cilostazol in Patients Undergoing Internal Carotid Artery Stent Placement

Aspirin and clopidogrel have been demonstrated to be safe in the setting of extracranial carotid artery stenting. The IDEALCAST (Investigation on Devices and Antiplatelet Therapy for Carotid Artery Stenting) investigators conducted a multicenter prospective observational study on the onset of vascular events after carotid artery stenting in an effort to find out the efficacy and safety of carotid artery stenting in Japan and to investigate the effects of antiplatelet drugs administered before and after carotid artery stenting on efficacy and safety of carotid artery stenting. A total of 949 patients with extracranial carotid artery stenosis were enrolled and 934 had carotid artery stents placed with antiplatelet drugs and were followed for 1 year. The primary end point (incidence of the first event of death, ischemic stroke, hemorrhagic stroke, transient ischemic attack, myocardial infarction, or serious hemorrhage within 1 year after enrollment) was observed in 69 patients (7.4\%) within 30 days of enrollment and in 40 patients (4.3\%) between 31 days and 1 year after enrollment. The choice of antiplatelet agents in the periprocedural period was up to the investigators. The incidence of the first event for aspirin and cilostazol was significantly lower than that for aspirin and clopidogrel $(p=0.01)$, aspirin and clopidogrel and cilostazol $(p=0.01)$, and antiplatelet monotherapy $(p<0.01)$ [9].

One of the limitations of bare metal stent implantation is the restenosis secondary to intimal hyperplasia within or adjacent to the stent $[19,20]$. Cilostazol has been found to reduce neointimal formation in balloon-injured rat carotid arteries and inhibits restenosis after percutaneous transluminal coronary angioplasty [21, 22]. Takayama et al. [13] performed a retrospective, multicenter trial of 62 carotid artery lesions in 60 patients, studying the restenosis rate following carotid artery stenting with the carotid wall stent. There was a cilostazol (aspirin, $100 \mathrm{mg}$, and cilostazol, $200 \mathrm{mg} ; n=30$ ) and non-cilostazol group (aspirin, $100 \mathrm{mg}$, and clopidogrel, $75 \mathrm{mg}[n=29]$, or ticlopidine, $100 \mathrm{mg}[n=2]$ or $200 \mathrm{mg}[n=1])$. The two antiplatelet medications were given 1 week preoperatively and continued for at least 3 months postoperatively. The patients were followed at 3 and 6 months postoperatively with an angiographic study. Takayama et al. [13] found that there were 5 cases of asymptomatic restenosis (8.3\%) (4 were from the aspirin and clopidogrel group, and 1 was from the ticlopidine group) but none in the cilostazol treatment group, and the difference was statistically significant ( $p=0.0239)$.

This study was intended to demonstrate the safety and feasibility of the addition of cilostazol to aspirin prior to and following extracranial carotid artery stenting, but there are limitations. One limitation of the study is the small sample size and its open-label design. The subjects were not randomized with a comparator group, and the results may not be representative of patients with characteristics different from the inclusion and exclusion criteria used.

\section{Conclusion}

The use of cilostazol and aspirin for internal carotid artery stent placement appears to be safe, but protocol compliance needs to be emphasized. Further studies are required to analyze the effectiveness and role of cilostazol in neurointerventional procedures.

\section{Statement of Ethics}

All the research meets the ethical guidelines, including adherence to the legal requirements of the study country.

\section{Disclosure Statement}

None of the authors involved in the study had any conflict of interest. 


\begin{tabular}{l|l}
\hline Intervent Neurol 2017;6:42-48 \\
\hline DOI: 10.1159/000452308 & $\begin{array}{l}\text { ( ) 2016 S. Karger AG, Basel } \\
\text { www.karger.com/ine }\end{array}$ \\
\hline
\end{tabular}

Hassan et al.: Open-Label Phase I Clinical Study to Assess the Safety and Efficacy of Cilostazol in Patients Undergoing Internal Carotid Artery Stent Placement

\section{References}

1 Pan X, Arauz E, Krzanowski JJ, Fitzpatrick DF, Polson JB: Synergistic interactions between selective pharmacological inhibitors of phosphodiesterase isozyme families PDE III and PDE IV to attenuate proliferation of rat vascular smooth muscle cells. Biochem Pharmacol 1994;48:827-835.

2 Hidaka H, Hayashi H, Kohri H, Kimura Y, Hosokawa T, Igawa T, et al: Selective inhibitor of platelet cyclic adenosine monophosphate phosphodiesterase, cilostamide, inhibits platelet aggregation. J Pharmacol Exp Ther 1979;211:26-30.

3 Kim MJ, Park KG, Lee KM, Kim HS, Kim SY, Kim CS, et al: Cilostazol inhibits vascular smooth muscle cell growth by downregulation of the transcription factor E2F. Hypertension 2005;45:552-556.

4 Yoo AR, Koh SH, Cho GW, Kim SH: Inhibitory effects of cilostazol on proliferation of vascular smooth muscle cells (VSMCs) through suppression of the ERK1/2 pathway. J Atheroscler Thromb 2010;17:1009-1018.

5 Sorkin EM, Markham A: Cilostazol. Drugs Aging 1999;14:63-71; discussion 72-73.

6 Thompson PD, Zimet R, Forbes WP, Zhang P: Meta-analysis of results from eight randomized, placebocontrolled trials on the effect of cilostazol on patients with intermittent claudication. Am J Cardiol 2002;90: 1314-1319.

7 Shinohara Y, Katayama Y, Uchiyama S, Yamaguchi T, Handa S, Matsuoka K, et al: Cilostazol for prevention of secondary stroke (CSPS 2): an aspirin-controlled, double-blind, randomised non-inferiority trial. Lancet Neurol 2010;9:959-968.

8 Brott TG, Halperin JL, Abbara S, Bacharach JM, Barr JD, Bush RL, et al: 2011 ASA/ACCF/AHA/AANN/AANS/ ACR/ASNR/CNS/SAIP/SCAI/SIR/SNIS/SVM/SVS guideline on the management of patients with extracranial carotid and vertebral artery disease: executive summary: a report of the American College of Cardiology Foundation/American Heart Association Task Force on Practice Guidelines, and the American Stroke Association, American Association of Neuroscience Nurses, American Association of Neurological Surgeons, American College of Radiology, American Society of Neuroradiology, Congress of Neurological Surgeons, Society of Atherosclerosis Imaging and Prevention, Society for Cardiovascular Angiography and Interventions, Society of Interventional Radiology, Society of NeuroInterventional Surgery, Society for Vascular Medicine, and Society for Vascular Surgery. Vasc Med 2011;16:35-77.

9 Sakai N, Yamagami H, Matsubara Y, Ezura M, Hyodo A, Matsumaru Y, et al: Prospective registry of carotid artery stenting in Japan - Investigation on Device and Antiplatelet for Carotid Artery Stenting. J Stroke Cerebrovasc Dis 2014;23:1374-1384.

10 Tsuchikane E, Fukuhara A, Kobayashi T, Kirino M, Yamasaki K, Izumi M, et al: Impact of cilostazol on restenosis after percutaneous coronary balloon angioplasty. Circulation 1999;100:21-26.

11 Douglas JS Jr, Holmes DR Jr, Kereiakes DJ, Grines CL, Block E, Ghazzal ZM, et al: Coronary stent restenosis in patients treated with cilostazol. Circulation 2005;112:2826-2832.

12 Park SW, Lee CW, Kim HS, Lee NH, Nah DY, Hong MK, et al: Effects of cilostazol on angiographic restenosis after coronary stent placement. Am J Cardiol 2000;86:499-503.

13 Takayama K, Taoka T, Nakagawa H, Myouchin K, Wada T, Sakamoto M, et al: Effect of cilostazol in preventing restenosis after carotid artery stenting using the carotid wallstent: a multicenter retrospective study. AJNR Am J Neuroradiol 2012;33:2167-2170.

14 Ferguson GG, Eliasziw M, Barr HW, Clagett GP, Barnes RW, Wallace MC, et al: The North American Symptomatic Carotid Endarterectomy Trial: surgical results in 1,415 patients. Stroke 1999;30:1751-1758.

15 Yadav JS, Wholey MH, Kuntz RE, Fayad P, Katzen BT, Mishkel GJ, et al: Protected carotid-artery stenting versus endarterectomy in high-risk patients. N Engl J Med 2004;351:1493-1501.

16 The GUSTO investigators: An international randomized trial comparing four thrombolytic strategies for acute myocardial infarction. N Engl J Med 1993;329:673-682.

17 Khan M, Qureshi AI: Factors associated with increased rates of post-procedural stroke or death following carotid artery stent placement: a systematic review. J Vasc Interv Neurol 2014;7:11-20.

18 Shim CY, Yoon SJ, Park S, Kim JS, Choi JR, Ko YG, et al: The clopidogrel resistance can be attenuated with triple antiplatelet therapy in patients undergoing drug-eluting stents implantation. Int J Cardiol 2009;134:351-355.

19 Doyle B, Rihal CS, O'Sullivan CJ, Lennon RJ, Wiste HJ, Bell M, et al: Outcomes of stent thrombosis and restenosis during extended follow-up of patients treated with bare-metal coronary stents. Circulation 2007;116:23912398.

20 Wiisanen ME, Abdel-Latif A, Mukherjee D, Ziada KM: Drug-eluting stents versus bare-metal stents in saphenous vein graft interventions: a systematic review and meta-analysis. JACC Cardiovasc Interv 2010;3:1262-1273.

21 Ishizaka N, Taguchi J, Kimura Y, Ikari Y, Aizawa T, Togo M, et al: Effects of a single local administration of cilostazol on neointimal formation in balloon-injured rat carotid artery. Atherosclerosis 1999;142:41-46.

22 Kawabe-Yako R, Ii M, Masuo O, Asahara T, Itakura T: Cilostazol activates function of bone marrow-derived endothelial progenitor cell for re-endothelialization in a carotid balloon injury model. PLoS One 2011; $6: \mathrm{e} 24646$. 